\title{
Synthesis of Embryonic Zeolites with Controlled Physicochemical Properties
}

\author{
Mariame Akouche, ${ }^{\dagger}$ Jean-Pierre Gilson, ${ }^{\dagger}$ Nikolai Nesterenko, ${ }^{\dagger}$ Simona Moldovan, ${ }^{\top}$ Daniel Chateigner, ${ }^{\top}$ \\ Hussein El Siblani, ${ }^{\dagger}$ Delphine Minoux ${ }^{\ddagger}$ Jean-Pierre Dath, ${ }^{\dagger}$ Valentin Valtchev ${ }^{\dagger} * *$ \\ ${ }^{\dagger}$ Normandie Univ, ENSICAEN, UNICAEN, CNRS, Laboratoire Catalyse et Spectrochimie, 14000 Caen, France. \\ * Total Research and Technology Feluy (TRTF), Zone Industrielle C, 7181 Feluy, Belgium. \\ ${ }^{\mathrm{T}}$ Institut des Sciences Appliquées de Rouen, Groupe de Physique des Matériaux (GPM), Rouen University, 76801 Rouen, \\ France. \\ ${ }^{7}$ Normandie Univ, ENSICAEN, UNICAEN, CNRS, Laboratoire de Cristallographie et Science des Matériaux, 14000 \\ Caen, France.
}

\begin{abstract}
Colloidal zeolite precursors, with a sharp particle size distribution (ca. 3-5 nm) and identical chemical composition, the so-called embryonic zeolites (EZs), are prepared by a strict control of aluminosilicate precursors polymerization in zeoliteyielding systems. The organic structure directing agent (OSDA) acts as a sacrificial template and is eliminated by high temperature combustion after the synthesis. Physicochemical properties of the EZs, such as pore size and volume and specific surface area are determined by the size of the OSDA and the synthesis conditions employed; i.e. the larger the OSDA, the higher the microporous volume and the specific surface area of the derived EZs. The EZs belong to the family of extra-large microporous (1-2.5 $\mathrm{nm}$ ) materials. Upon calcination EZs retain their structure/porosity, and most of their aluminum remains in tetrahedral coordination to provide Brønsted acidity. Pyridine adsorption shows a lower acidic strength for embryonic zeolites with respect to their crystalline

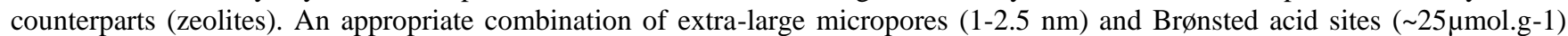
leads to improved catalytic performances in the dealkylation of TiPBz, a proxy for bulky molecules reacting only on the external surface of crystalline zeolites. By varying the size of the OSDA for synthesizing the EZ, materials with controlled porosity, acidity, accessibility, and catalytic activity are prepared and their properties extend those of existing crystalline zeolites.
\end{abstract}

\section{INTRODUCTION}

Molecular sieve zeolites are widely used as heterogenous catalysts in a variety of industrial (oil refining, petro- and fine chemicals production..) and environmental (exhaust gas treatment, heavy and radioactive ion sequestration, ...) applications. ${ }^{1-2}$ They typically offer high surface area, uniform micropores with well-defined topology, strong acid sites, and high thermal and chemical stability. ${ }^{3-5}$ A unique property of zeolite materials is their shape selectivity, ${ }^{3}$ a consequence of their active sites being confined in well-defined micropore spaces. However, the presence of such micropores often imposes transport limitations on reactants and products, in particular, those with a size close to or larger than the pore diameter. ${ }^{5}$ These steps become rate determining in the catalytic activity and the full potential of theses catalysts is not reached. In the case of bulky molecules, larger than zeolite pores, the only accessible and active sites are those located on the outer surface of the crystals and their pore openings.

In summary, the problems of diffusion and related low accessibility to the active sites represent a major roadblock in a number of industrial reactions catalyzed by zeolites (cracking, oxidation, esterification, ...). To meet exacting industrial requirements, ${ }^{6}$ much efforts are devoted to preparing zeolite materials with better accessibility and improved transport properties. The most explored avenues to improve catalytic performances were focused on decreasing zeolite crystal size $\mathrm{s}^{7-11}$ and preparing zeolites containing a system of larger (meso-)pores. ${ }^{12-17} \mathrm{~A}$ mesoporous network connected to the native micropores in zeolite crystals decreases mass transport limitations, but it does not affect the limited intrinsic ability of zeolites to process bulky molecules. Both solutions, nano-zeolites and mesopore-containing zeolites, bear some limitations, in particular the active sites in the zeolite channels remain inaccessible for bulky molecules, and therefore alternative solutions are required.

Recently, we addressed this issue by the preparation of zeolites units with sizes of few nanometers. ${ }^{18}$ These units denoted "embryonic zeolites" exhibit only short-range order and comprise elements of zeolite structure. Their semi-formed unit cells offer easier access of much bulkier molecules to the active sites than their fully crystalline counterpart, which exhibits long range order. The embryonic zeolites were prepared as mono disperse suspension containing nano particles that are uniform in size and composition. ${ }^{18}$ They exhibit superior catalytic activity, with respect to the fully crystalline material (zeolite) synthesized from the same initial system.

For instance, embryonic zeolites synthesized with tetrapropylammonium as structure directing agent exhibit pores in the 
range 1-2 nm. The extension of zeolite pore size to 1-2 $\mathrm{nm}$ would allow to process much bulkier molecules than the "current" available zeolites can process. At present, only Gesilicate zeolites exhibit pores larger than $1 \mathrm{~nm},{ }^{19}$ while the conventional alumino-silicate zeolites are limited to $1 \mathrm{~nm}$ in pore size. Unfortunately, the limited (hydro)thermal stability of Ge-silicate zeolites so far precluded their commercial used. Thus, the quest for extra-large pore zeolitic materials continues to be a topic of high priority. Here, we address this issue by the preparation of a few nanometer large zeolitic nano units which offer full accessibility to their active sites by relaxing diffusion limitations.

Sacrificial organic templates are commonly used in the synthesis of nanoporous materials. ${ }^{20-21}$ In the synthesis of zeolitic materials the organic template, often called organic structure directing agent (OSDA) plays a key role in the formation of zeolite structure and charge distribution in the framework. ${ }^{19}$ In general, these are positively charged molecules that balance the negative charge introduced by $\mathrm{Al}$ cations in the zeolite framework. Each OSDA has a fixed size/charge ratio; therefore, the total guest volume is determined by the number of guest molecules that will correspond to the framework charge density. ${ }^{22-24}$

The objective of this study is the preparation of embryonic zeolites with pores exceeding $1 \mathrm{~nm}$ with a few nanometer particle size and controlled pore size and pore volume. A series of tetraalkylammonium (TAA) cations with size ranging between 6 and $12 \AA$ was employed. The series includes: tetramethylammonium $\left(\mathrm{TMA}^{+}\right)$, tetrapropylammonium $\left(\mathrm{TPA}^{+}\right)$, trimethyladamantylammonium $\left(\mathrm{TMAd}^{+}\right)$, tetrabutylammonium $\left(\mathrm{TBA}^{+}\right)$and tetrahexylammonium $\left(\mathrm{THA}^{+}\right)$. With the exception of $\mathrm{THA}^{+}$, which is too big to yield a zeolite-type microporous material, all other OSDA generate zeolite structures. ${ }^{25}$ Embryonic zeolites with different micropore volumes and specific surrface areas are obtained. Their catalytic activities are evaluated in the dealkylation of a model molecule, 1,3,5-triisopropylbenzene (1,3,5-TiPBz) hardly penetrating the micropores of any industrially relevant zeolite. It is, therefore, commonly used to study the external surface properties of zeolites, including those with the large pores. ${ }^{26,27}$

\section{EXPERIMENTAL SECTION}

\section{Preparation of embryonic precursors}

All syntheses started from clear homogenous sols with molar composition 9OSDA : $0.25 \mathrm{Al}_{2} \mathrm{O}_{3}: 25 \mathrm{SiO}_{2}: 430 \mathrm{H}_{2} \mathrm{O}$ : 100EtOH, where OSDA: Tetramethylammonium hydroxide (TMA.OH $25 \%$ in water, Alfa Aesar), Tetrapropylammonium hydroxide (TPA.OH $20 \%$ in water, Alfa Aesar) Trimethyladamantylammonium hydroxide (TMAd.OH $25 \%$ in water, Sachem), Tetrabutylammonium hydroxide (TBA.OH $40 \%$ in water, Alfa Aesar) and Tetrahexylammonium hydroxide (THA.OH 20\% in water, Sigma Aldrich). After mixing the OSDA with distilled water, aluminum sulfate $(98 \%)$ and tetraethylorthosilicate (TEOS 98\%), the solution was hydrolyzed at room temperature for $6 \mathrm{~h}$ in a closed polypropylene bottle. The complete hydrolysis was confirmed by the appearance of a clear monophasic solution. Then, this solution was either dried by freeze drying at $-94^{\circ} \mathrm{C}$ under vacuum (to avoid any further crystallization) or hydrothermally treated at $90^{\circ} \mathrm{C}$ for 12,15 , 18,144 and $216 \mathrm{~h}$ as the kinetics of the synthesis depends on the nature of the OSDA. After the synthesis, the solid was recovered by freeze drying and further calcined at $550^{\circ} \mathrm{C}$ for $5 \mathrm{~h}$ in a static oven under air.
The following series of zeolite precursor (P) samples were prepared by:

- Room temperature synthesis $\left(\mathrm{P}_{\mathrm{RT}}\right)$ : $\mathrm{P}_{\mathrm{RT}}$-TMA, $\mathrm{P}_{\mathrm{RT}}-\mathrm{TPA}, \mathrm{P}_{\mathrm{RT}}-$ TBA, $\mathrm{P}_{\mathrm{RT}^{-}}$TMAd, and $\mathrm{P}_{\mathrm{RT}}$-THA.

- Hydrothermal synthesis: $\mathrm{P}_{\mathrm{x}-\mathrm{y}}-\mathrm{SDA}$, where $\mathrm{x}$ is the temperature in ${ }^{\circ} \mathrm{C}$; and y the crystallization time in $\mathrm{h}$; ex: $\mathrm{P}_{90-15}$-TMA, $\mathrm{P}_{90-216^{-}}$TMAd, ...

A highly crystalline nano-sized ZSM-5 prepared from the same initial suspension at $100{ }^{\circ} \mathrm{C}$ for $48 \mathrm{~h}$ was used as a reference sample.

\section{Characterization}

All materials were characterized by powder X-ray diffraction (PXRD) using a PANalytical X'Pert Pro diffractometer with average $\mathrm{Cu} \mathrm{K} \alpha$ radiation $(\lambda=1.5418 \AA)$. We used a $\theta-2 \theta$ scan in the $3-50^{\circ} 2 \theta$-range and a $0.02^{\circ}$ step. The whole pattern was fitted using the combined analysis formalism ${ }^{28}$ implemented in the MAUD program ${ }^{29}$ a software using an extended Rietveld ${ }^{30}$ analysis approach. Since severe line broadening was observed in the diffraction diagrams, we analyzed those within the Combined Analysis approach. The instrumental contribution to the line broadening was calibrated on the LaB6 srm660b standard powder from the National Institute of Standards and Technology. The Popa ${ }^{31}$ formalism was then used to describe anisotropic crystallite sizes and shapes. No preferred orientation was detected during the fit. The ZSM5 structural model $\mathrm{n}^{\circ} 1505105$ from the Crystallography Open Database ${ }^{32}$ was used as a starting model in the refinement.

Nitrogen adsorption measurements were carried out on a Micromeritics ASAP 2020 surface area analyzer. The calcined samples were analyzed after degassing at $300{ }^{\circ} \mathrm{C}$. The isotherms were recorded using the ASAP 2020 analysis program. The microporous volume $\left(\mathrm{V}_{\text {mic }} / \mathrm{cm}^{3} \cdot \mathrm{g}^{-1}\right)$ and the external surface area (Sext $/ \mathrm{m}^{2} \cdot \mathrm{g}^{-1}$ ) were obtained from the t-plot method based on the Harkins-Jura equation. The macro- and mesopores size distribution was obtained from the desorption branch using the Barrett Joyner Halenda algorithm assuming cylindrical pores. For refined analysis, micro-mesopores size distribution was extracted from Density Functional Theory modelling of the adsorption branch. TG-DSC measurements of different samples were carried out on a SETSYS evolution instrument (SETARAM). About $10 \mathrm{mg}$ of each sample was introduced in an alumina crucible that is loaded in the analyzer chamber. The sample was heated from $30{ }^{\circ} \mathrm{C}$ to $800{ }^{\circ} \mathrm{C}$ with a heating ramp of $5{ }^{\circ} \mathrm{C} \cdot \mathrm{min}^{-1}$ under air (flow rate: $40 \mathrm{~mL} \cdot \mathrm{min}^{-1}$ ).

All NMR measurements were done with 4-OD mm zirconia rotors and with a spinning speed of $12 \mathrm{kHz}$. The solid state ${ }^{2}$ ${ }^{13} \mathrm{C}$ CP-MAS NMR spectra were recorded on a Bruker Avance 400 spectrometer operating at $100.6 \mathrm{MHz}$. During the pulse program, a $\pi / 2$ pulse of $3.7 \mu \mathrm{s}$ on ${ }^{1} \mathrm{H}$, a contact time of $2 \mathrm{~ms}$ and a recycle delay of $2 \mathrm{~s}$ were used. ${ }^{27} \mathrm{Al}$ MAS NMR was recorded on a Bruker Avance 500 spectrometer operating at 130.3 MHz. ${ }^{27} \mathrm{Al}$ MAS NMR was obtained with a $\pi / 12$ pulse and a recycle delay of $1 \mathrm{~s}$. The amount of nontetrahedral Al was estimated by the integration of peak area using Dm-fit program. The results were verified by the Top Spin program. The solid state ${ }^{29} \mathrm{Si}$ NMR (1pulse) was also recorded on Brucker Avance III-HD 500 spectrometer (11.7 T) operating at $99.3 \mathrm{MHZ}$, using zirconia rotors of $4 \mathrm{~mm}$ outer diameter spun at $12 \mathrm{KHZ}$. A single pulse excitation $\left(30^{\circ}\right.$ flip angle) is used with a recycle delay of 30s. TMS was the reference for ${ }^{29} \mathrm{Si}$ and ${ }^{13} \mathrm{C}$ while a $1 \mathrm{M} \mathrm{Al}\left(\mathrm{NO}_{3}\right)_{3}$ solution was used for ${ }^{27} \mathrm{Al}$. 
${ }^{129} \mathrm{Xe}$ NMR experiments were performed on a Bruker AV III 400 wide-bore spectrometer equipped with a $10 \mathrm{~mm}$ BBO probe, operating at a frequency of $110.64 \mathrm{MHz}$ for ${ }^{129} \mathrm{Xe}$. Prior to each experiment, the sample was introduced into a home designed (10 mm O.D.) NMR tube and dehydrated under high vacuum overnight at $413 \mathrm{~K}$. The hyperpolarized $(\mathrm{HP}){ }^{129} \mathrm{Xe}$ gas was obtained using a home-built xenon polarizer based on the spin-exchange optical pumping (SEOP) technique. ${ }^{33-34} \mathrm{HP}$ ${ }^{129} \mathrm{Xe}$ NMR spectra were acquired under a continuous recirculating flow of $50 \mathrm{~mL} \cdot \mathrm{min}-1$ of a gas mixture containing $4 \% \mathrm{Xe}, 6 \% \mathrm{~N}_{2}$ and $90 \% \mathrm{He}$ at a total absolute pressure of 1.5 bar. For all variable-temperature (VT) measurements and after each temperature change performed at a speed of $5 \mathrm{~K} \cdot \mathrm{min}^{-1}$, a delay of $\sim 20$ min was generally necessary to ensure a homogeneous temperature all over the sample, and this stability was checked by directly monitoring the xenon chemical shifts. All spectra were referenced to free xenon gas at $0 \mathrm{ppm}$. The IR spectra were recorded on a SHIMADZU IR Affinity-1 Fourier Transform Infrared Spectrophotometer using the $\mathrm{KBr}$ pellet technique. Pyridine and collidine adsorption were used to evaluate the acidity and accessibility of the samples. The study was performed using a standard in-situ FTIR set-up. Infrared spectra were recorded on a Nicolet Magna 550 FTIR spectrometer equipped with a DTGS detector at $4 \mathrm{~cm}^{-1}$ optical resolution, with one level of zero-filling for the Fourier transform. Prior to the measurement, the sample was grinded and pressed into a self-supporting disc (diameter: $2 \mathrm{~cm}$, approx. 5 $\mathrm{mg} \mathrm{cm}{ }^{-2}$ ) and activated in vacuum (ca. $10^{-6} \mathrm{hPa}$ ) at $460{ }^{\circ} \mathrm{C}$ for $2 \mathrm{~h}$ at $2{ }^{\circ} \mathrm{C} \cdot \mathrm{min}^{-1}$. After cooling to room temperature, the spectrum of the sample was recorded for further use as a reference. Then, a pressure of $1.33 \mathrm{hPa}$ of probe molecule (P.M.) was established in the cell at ambient temperature to reach saturation. The wafer was heated at $100{ }^{\circ} \mathrm{C}$ for $15 \mathrm{~min}$ to facilitate diffusion of P.M. into the sample. Successive evacuations were performed at $25{ }^{\circ} \mathrm{C}, 50{ }^{\circ} \mathrm{C}, 100{ }^{\circ} \mathrm{C}, 150{ }^{\circ} \mathrm{C}, 200{ }^{\circ} \mathrm{C}, 250$ ${ }^{\circ} \mathrm{C}, 300{ }^{\circ} \mathrm{C}$, and $350{ }^{\circ} \mathrm{C}$ at 15 min intervals. All spectra were normalized to $2.5 \mathrm{mg} \mathrm{cm}^{-2}$ wafer. The amounts of acidic sites were determined using the areas of the bands at $1450 \mathrm{~cm}^{-1}$ (Lewis) and $1545 \mathrm{~cm}^{-1}$ (Brønsted) in case of pyridine adsorption and at $1644 \mathrm{~cm}^{-1}$ (Brønsted) in case of collidineadsorption. The molar extinction coefficients $(\mathcal{E})$ used for

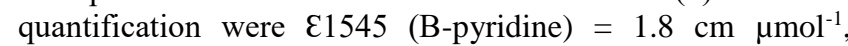

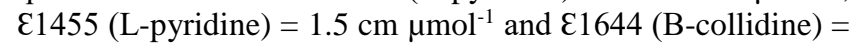

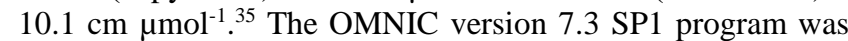
used for data processing.

The Transmission Electron Microcopy (TEM) investigations were carried out on a double corrected Cold FEG Jeol ARM Analytical TEM. Due to the materials high sensitivity to electron beam irradiation, an accelerated voltage of at $80 \mathrm{kV}$ was employed and the micrographs were acquired under Scanning TEM (STEM) mode using the High Angular Annular Dark Field (HAADF) detection methodology. In this approach, a $0.1 \mathrm{~nm}$ diameter beam scanned the region of interest and the image was recorded at a camera length of $8 \mathrm{~cm}$ and in the semi angular range $70-280 \mathrm{mrad}$. Size calibrated $\mathrm{Au}$ NP were employed for the STEM fine alignments. The images were acquired at a speed of $12 \mu \mathrm{s} / \mathrm{px}$ for image sizes of $1024 \times 1024$ px using the Digiscan Plugin implemented in the Digital Micrograph software. Few drops of an ethanol-based solution containing the specimens dispersed in ethanol and using ultrasounds were deposited on a holey-carbon membrane disposed on 300 mesh $\mathrm{Cu}$-grids.

Catalytic testing
The catalytic performances were evaluated in the dealkylation of 1,3,5-triisopropylbenzene (TiPBz) in a down flow atmospheric reactor. In a typical catalytic test, $20 \mathrm{mg}$ of catalyst (dry mass) was loaded at the center of a stainless-steel tubular reactor (internal diameter of 1/2") and activated in-situ at 460 ${ }^{\circ} \mathrm{C}$ (ramping from room temperature at $5{ }^{\circ} \mathrm{C} \cdot \mathrm{min}^{-1}$ ) under a dry air flow $\left(50 \mathrm{ml} \cdot \mathrm{min}^{-1}\right)$ for $1 \mathrm{~h}$. The temperature was subsequently lowered to $300{ }^{\circ} \mathrm{C}$ under nitrogen flow $\left(50 \mathrm{ml} \cdot \mathrm{min}^{-1}\right)$. The nitrogen flow was then diverted to a saturator (operated at $70{ }^{\circ} \mathrm{C}$ ) filled with TiPBz (Alfa Aesar, 97\%), generating a TiPBz partial pressure of $170 \mathrm{~Pa}$ feeding the reactor. The WHSV (Weight Hourly Space Velocity) was held constant at $8 \mathrm{~h}^{-1}$ for all tests. The conversions were measured at $300^{\circ} \mathrm{C}$ over $100 \mathrm{~min}$. The online analysis of the products and unconverted reactant, transferred via a line heated at $150{ }^{\circ} \mathrm{C}$ to a gas sampling valve, were monitored by a Varian CP-3800 Gas Chromatograph equipped with a flame ionization detector (FID) detector and a HP-PONA cross-linked methyl siloxane column, $50 \mathrm{~m}$ (L) x $0.2 \mathrm{~mm}$ (ID) x $0.5 \mu \mathrm{m}$ (film thickness). The temperature of the column was kept at $160{ }^{\circ} \mathrm{C}$ throughout the measurement. The injection temperature was maintained at $200{ }^{\circ} \mathrm{C}$ while the detection temperature was maintained at 250 ${ }^{\circ} \mathrm{C}$.

\section{RESULTS AND DISCUSSION}

Discrete nanometer sized embryonic zeolites can only be obtained if the polymerization between silica and alumina precursor species and the OSDA is closely controlled, to avoid the formation of large and dense gel particles with various sizes and compositions. This is also a necessary condition to assess their physicochemical properties. Such a general rule is particularly important with amorphous material lacking long range structural order. Optically clear sols containing only discrete gel particles are therefore used in all our syntheses to harvest solids with similar size, composition, and porosity.

Impact of OSDA on the physicochemical properties of embryonic zeolites.

Alkylammonium cations of varying sizes acting as organic structure directing agents (OSDAs) allow studying the properties of the porous solids harvested from syntheses performed at room temperature (RT). After complete hydrolysis of the silica source (TEOS), the resulting samples are freeze dried and characterized.

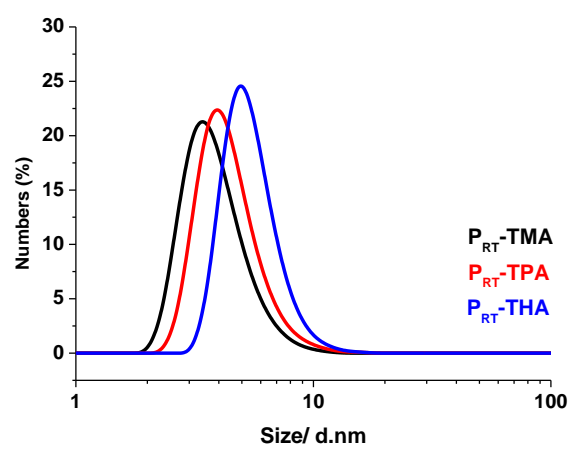

Figure 1. The particle size distribution of $P_{R_{T}}$-TMA, $P_{R T}-T P A$ and $\mathbf{P}_{\mathrm{RT}}$-THA suspensions.

According to DLS, all precursor sols present a monomodal particular size distribution with a size between 1 and $10 \mathrm{~nm}$, Figure 1. The size of embryonic zeolites depends on the size of the template employed and a clear relation is observed: maxima in the DLS peak of $\mathrm{P}_{\mathrm{RT}^{-}}$TMA, $\mathrm{P}_{\mathrm{RT}}-\mathrm{TPA}$, and $\mathrm{P}_{\mathrm{RT}^{-}}$ 
THA are $2 \mathrm{~nm}, 3 \mathrm{~nm}$ and $4.5 \mathrm{~nm}$ respectively. The synthesis conditions are such that no material exhibits any long-range structural order, monitored by X-ray diffraction, Figure S1. An SEM inspection highlights a uniform mass of aggregated particles, Figure S2, at higher magnification, the grain-like structure of the particles building the aggregates appears. More information on the size and morphology of the embryon- ic zeolites was obtained by STEM-HAADF. Upon freezedrying, discrete particles are observed. Their size (3-5nm) matches well with the result of DLS analysis. The particles generally exhibit a spherical morphology with a rough surface most probably due to the presence of pores with diameters $<0.9 \mathrm{~nm}$ as indicated by the arrows in the inset of Figure 2B.
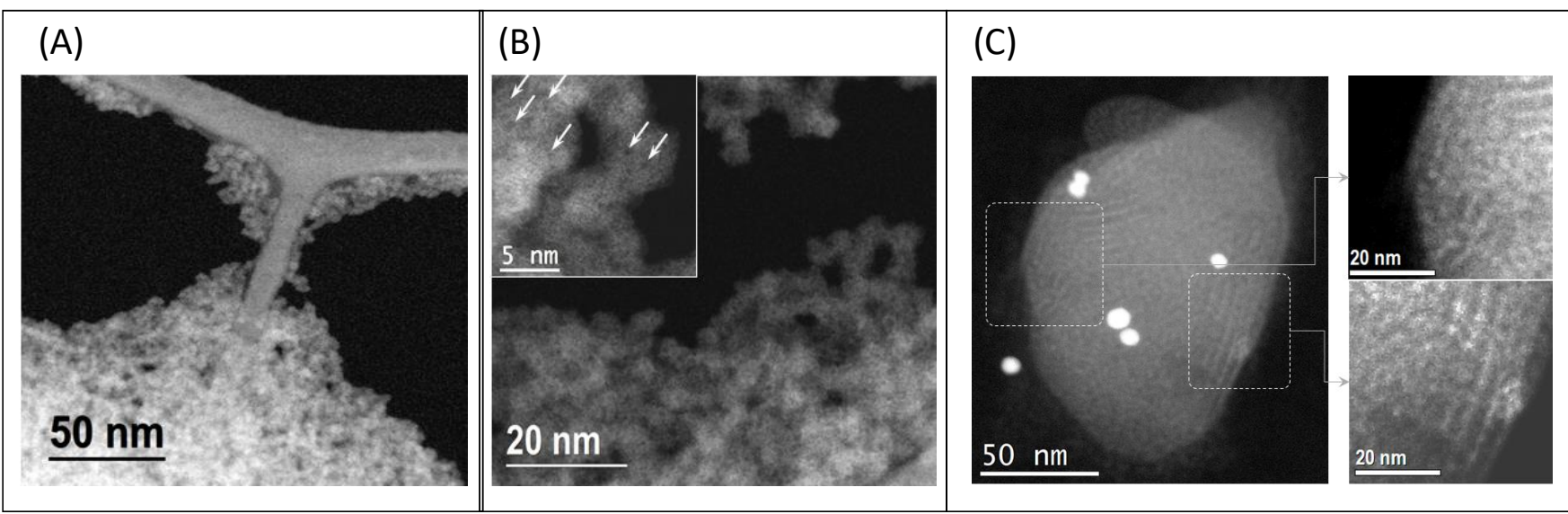

Figure 2. Low (A) and high (B) magnification view of freeze-dried $P_{\mathrm{RT}}$-TPA sample and colloidal crystal (C left) made of uniform in size $P_{\mathrm{RT}}$-TPA zeolite embryos and a high magnification view of the arrays of EZ building the colloidal crystals (C right). Note: the white spots in the left image are gold particles employed for the alignments.

Upon slow evaporation at room temperature, colloidal formation with arrays of individual EZ similar in size can be identified, Figure 2C. The formation of a crystal-like entity from the EZ shows the uniform nature of the colloidal suspen- sion obtained after the RT synthesis, where only discrete particles of similar size are present. Besides, the agglomerate exhibit area of short-range order with the spherical EZ as units.
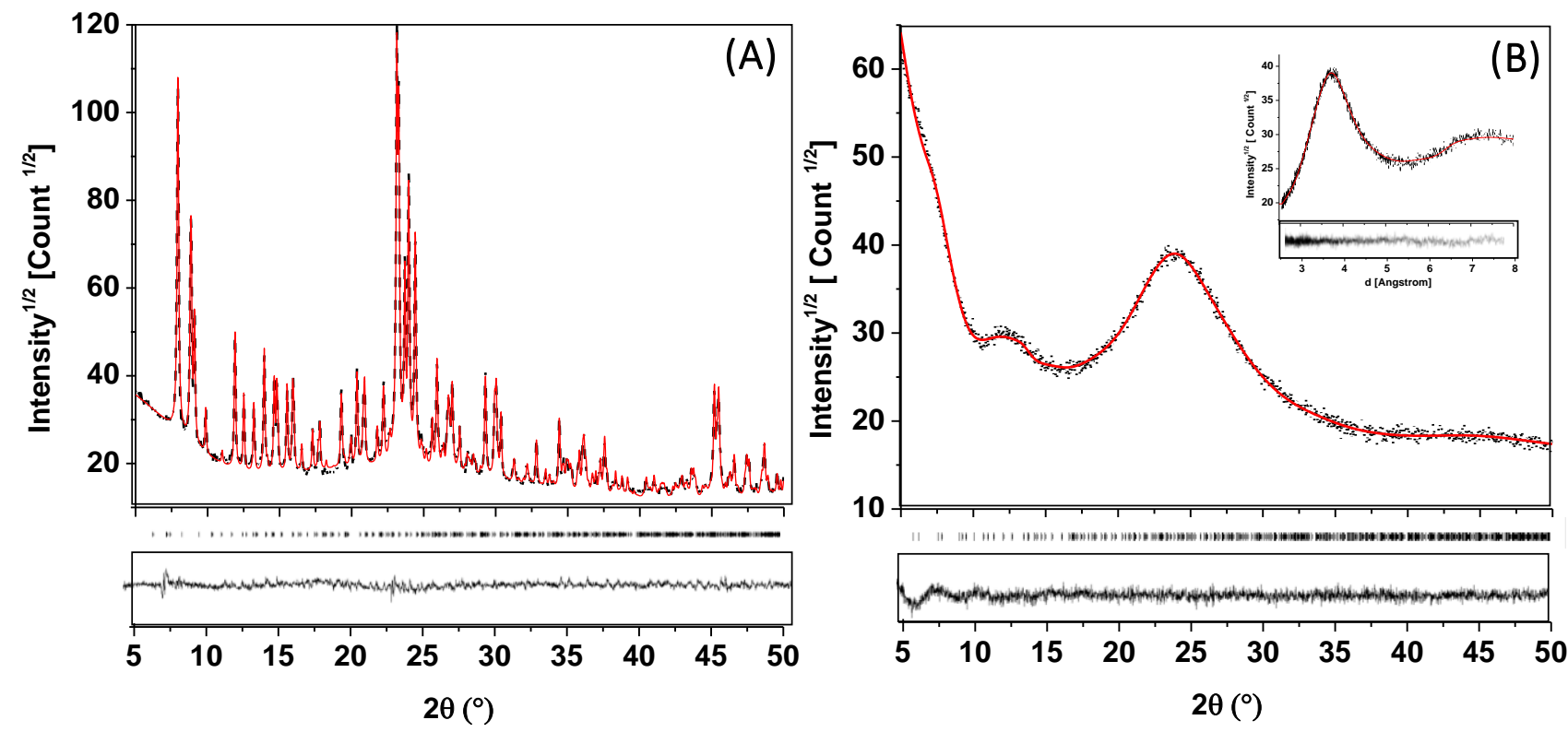

Figure 3. XRD diagrams and Rietveld fits for (A) well crystallized (mean crystallite sizes are 133(10) $\mathrm{nm}$; $\mathrm{GoF}=1.9)$ and $(\mathrm{B}) \mathrm{em}$ bryonic samples $(\mathrm{GoF}=1.2)$. Diagram bottoms are difference curves, insert in (B) is plotted in d-scale.

Figure 3 shows the difference in XRD diagrams between fully crystallized and amorphous EZ prepared with TPA. While the fully crystallized powder (see Figure 3A) clearly exhibits narrow diffraction peaks with cell parameters coherent with the original structure $(\mathrm{a}=2.00484(7) \mathrm{nm} ; \mathrm{b}=1.99267(6) \mathrm{nm}$; $\mathrm{c}=1.33919(5) \mathrm{nm})$, the amorphous sample (see Figure 3B) only gives rise to first- and second-order modulations due to closest and second closer neighboring atoms of the structure. We could fit this latter diagram using crystallite sizes typically of the order of the unit-cell (typically few nm), and significant microstrains (typically $0.05 \mathrm{rms}$ ), with slightly isotropized cell parameters $(\mathrm{a}=1.906(6) \mathrm{nm} ; \mathrm{b}=1.70(2) \mathrm{nm} ; \mathrm{c}=1.55(1) \mathrm{nm})$. 
Such fitted parameters are only helping the fit, but could not represent the first significant contribution appearing below $2 \theta$ $=10^{\circ}$. This latter contribution is associated with the periodical arrangement of the embryos depicted by the electron density contrasts observed in TEM images (see Figure 2C) and cannot be modeled in the XRD diagrams using the MFI-type structure. We instead used a simple Gaussian background contribution to account for it in the Rietveld fits. As a result (see Figure 3B insert), the first and second scattering contributions are located around 3.68 and 7.1 Angstroms, respectively. In MFI-type structure, such contributions characterize the mean distances between closest $\mathrm{Si}-\mathrm{O}$ polyhedra, with corresponding first and second scattering orders. The first distance at 3.68 Angstroms is also close to the one observed in fumed silica of around $3.9 \AA$ (see Figure S3A) while no periodicity is observed (see Figure S3B).

As X-ray diffraction is not the best technique to probe shortrange orders, on such embryonic zeolites we resorted to infrared spectroscopy (IR) to characterize the structure of ultrasmall zeolite embryos. The IR spectra display three main absorption bands around 1080 (with a shoulder at $1200 \mathrm{~cm}^{-1}$ ), 800 and $460 \mathrm{~cm}^{-1}$, Figure S4. The first two correspond to asymmetric and symmetric $\mathrm{Si}-\mathrm{O}$ stretching motions and the last one to a bending Si-O-Si mode. A shoulder at $560 \mathrm{~cm}^{-1}$ is also observed and assigned to the bending vibrations of external Si-O. ${ }^{36}$ The bands around 560 and $1200 \mathrm{~cm}^{-1}$ are generally attributed to the double-membered ring and external asymmetric stretching in the MFI structure, respectively ${ }^{37}$ while, the optical density ratio of 560 and $460 \mathrm{~cm}^{-1}$ bands is commonly used to determine the zeolite crystallinity. ${ }^{37}$ The crystallinities of the $\mathrm{P}_{\mathrm{RT}}$-TMA, $\mathrm{P}_{\mathrm{RT}}$-TPA, and $\mathrm{P}_{\mathrm{RT}}$-THA samples are similar according to such an IR study. The synthesized materials exhibit a type I isotherm with a significant uptake at low relative pressure followed by horizontal adsorption-desorption branches. A closer look at the isotherms reveals small differences between the material synthesized with TMA ( $\mathrm{P}_{\mathrm{RT}}$-TMA) and larger templates. The isotherm of $\mathrm{P}_{\mathrm{RT}}-\mathrm{TMA}$ is type Ia characteristic of ultra-micropores $(<0.7 \mathrm{~nm})$, whereas the others (TPA, TBA, TMAd, THA) are of type Ib, characteristic of super-micropores (1-2.5 nm) according to the classification of IUPAC. ${ }^{38}$ The latter isotherms show much higher uptake indicative of larger micropore volumes. The isotherm of nanosized ZSM-5 is included in Figure $\mathbf{4}$ and the data derived from the isotherm summarized in Table S1.

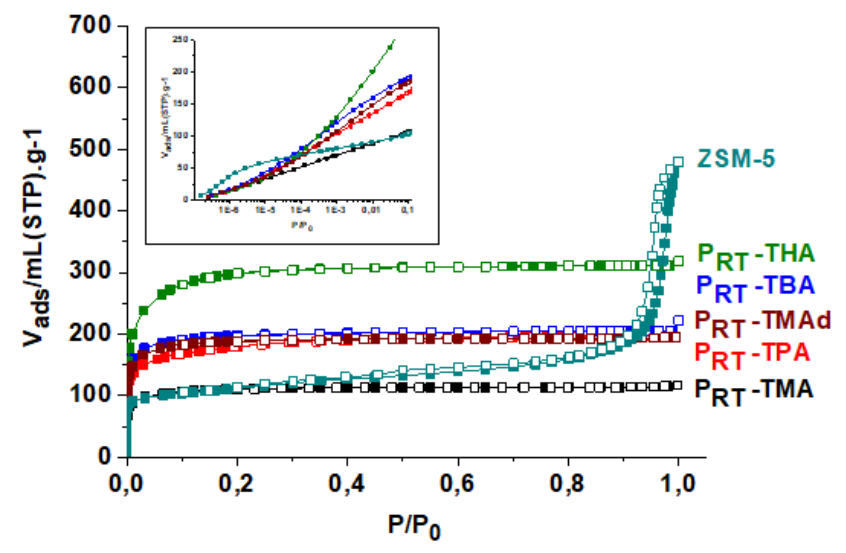

Figure 4. $\mathbf{N}_{2}$ adsorption/desorption isotherms of $\mathbf{P}_{\mathrm{RT}}$-SDA samples, where SDA is TMA, TPA, TMAd, TBA, and THA. The isotherm of nanosized ZSM-5 is included as a benchmark. The inset is plotted in the logarithmic $\mathrm{x}$-axis scale and represents the low $\left(<0.1 \mathrm{P} / \mathbf{P}_{0}\right)$ pressure range.

The micropore volume of the MFI type material is similar to $\mathrm{P}_{\mathrm{RT}}$-TMA and much lower than that of the embryos synthesized with larger templates. However, the total pore volume of the crystalline material is higher due to textural meso-porosity, revealed by the slope of the isotherm in the $0.2-0.8$ pressure range and the second uptake in the 0.9-1.0 range, between nanosized zeolite particles. Such a textural porosity is not present in the embryonic zeolite. If some textural pores exist, i.e. pores between ultra-small nano particles (3-4 nm) formed around the template, these pores remain in the microporous range.

The data summarized in Table $\mathbf{S 1}$ show that the microporous volume and specific surface area increase with the size of the SDA used. More precisely, $\mathrm{V}_{\text {micro }}$ and $\mathrm{S}_{\mathrm{BET}}$ increase from 0.17 to $0.47 \mathrm{~cm}^{3} \cdot \mathrm{g}^{-1}$ and from 418 to $1095 \mathrm{~m}^{2} \cdot \mathrm{g}^{-1}$ for TMA and THA, respectively. A small increase in micropore volume (TBA>TMAd $>$ TPA) is noticeable.

In general, templates with approximately similar sizes yield materials with very close specific surface area and micropore volume; a close positive correlation between the size of the OSDA and the $\mathrm{V}_{\text {micro }}$ and $\mathrm{S}_{\mathrm{BET}}$ is indeed observed on theses samples. It is well known that tetraalkylammonium cations play a key role in zeolite synthesis by ordering around them aluminosilicate species, akin to water clathrates, by progressive displacement of hydrogen bound water molecules. ${ }^{39-42}$ As long as synthesis is stopped before crystallization, the harvested materials are silica-alumina matrices organized around these OSDAs and form cages of different volumes depending on the size of SDA used.

The pore size distributions and the cumulative pore volumes of $\mathrm{P}_{\mathrm{RT}}$-TPA and $\mathrm{P}_{\mathrm{RT}}$-THA, extracted by DFT using a cylindrical geometry (model " $\mathrm{N}_{2}$-cylindrical pores-oxide surface") are displayed in Figure S5. The EZ prepared with TPA has a wide distribution of pore widths ranging between 8 and $20 \AA$ with the highest population of pores smaller than $14 \AA$; they correspond to a cumulative pore volume of $0.15 \mathrm{~cm}^{3} \cdot \mathrm{g}^{-1}$. Moreover, the EZ prepared in the presence of THA does not contain pores with size below $1 \mathrm{~nm}$. The population of large pores (> $14 \AA$ ) is the most largely presented in this sample. Despite their higher $\mathrm{V}_{\text {micro }}$ and $\mathrm{S}_{\mathrm{BET}}$, no additional larger pores are observed, so pores larger than $14 \AA$ dominate in this material. This is clear from the increase of their incremental volume and the decrease of the cumulative pore volume of pores smaller than $14 \AA$ from 0.15 to $0.09 \mathrm{~cm}^{3} \cdot \mathrm{g}^{-1}$. Some textural pores represented by a large peak centered at about $27 \AA$, present in $\mathrm{P}_{\mathrm{RT}}$-TPA. These data unambiguously imply that the size of the OSDA determines the pore size of the embryonic zeolites; a smaller OSDA yields pores of smaller width while larger OSDA leads to larger pores.

The pore structure of EZ can be studied by relating the confinement of Xe molecule to their chemical shift. ${ }^{43}$ Low chemical shift peaks, close to $0 \mathrm{ppm}$, indicate large (meso-)pores, while high chemical shifts indicate more confined space (micro) pores. The NMR spectra of $\mathrm{HP}^{129} \mathrm{Xe}$ adsorbed on the $\mathrm{P}_{\mathrm{RT}^{-}}$ TPA and $\mathrm{P}_{\mathrm{RT}}$-THA samples recorded at different temperatures are shown in Figure 5. In addition to the peak of xenon in the gas phase at $0 \mathrm{ppm}$, all spectra exhibit an additional resonance, which differs in $\mathrm{P}_{\mathrm{RT}}$-TPA and $\mathrm{P}_{\mathrm{RT}}$-THA samples. The $\mathrm{P}_{\mathrm{RT}}$-TPA material exhibits a single peak (136-92 ppm) in the 200-320 
$\mathrm{K}$ temperature range. The peak in $\mathrm{P}_{\mathrm{RT}}$-THA sample shifts from 115 to $84 \mathrm{ppm}$ in the $200-320 \mathrm{~K}$ temperature range. The higher chemical shift of Xe adsorbed in $\mathrm{P}_{\mathrm{RT}}$-TPA can be attributed to xenon atoms located in a more confined environment. This result is in good agreement with the physisorption measurements showing that the large THA template generated EZ with substantially higher pore volume.
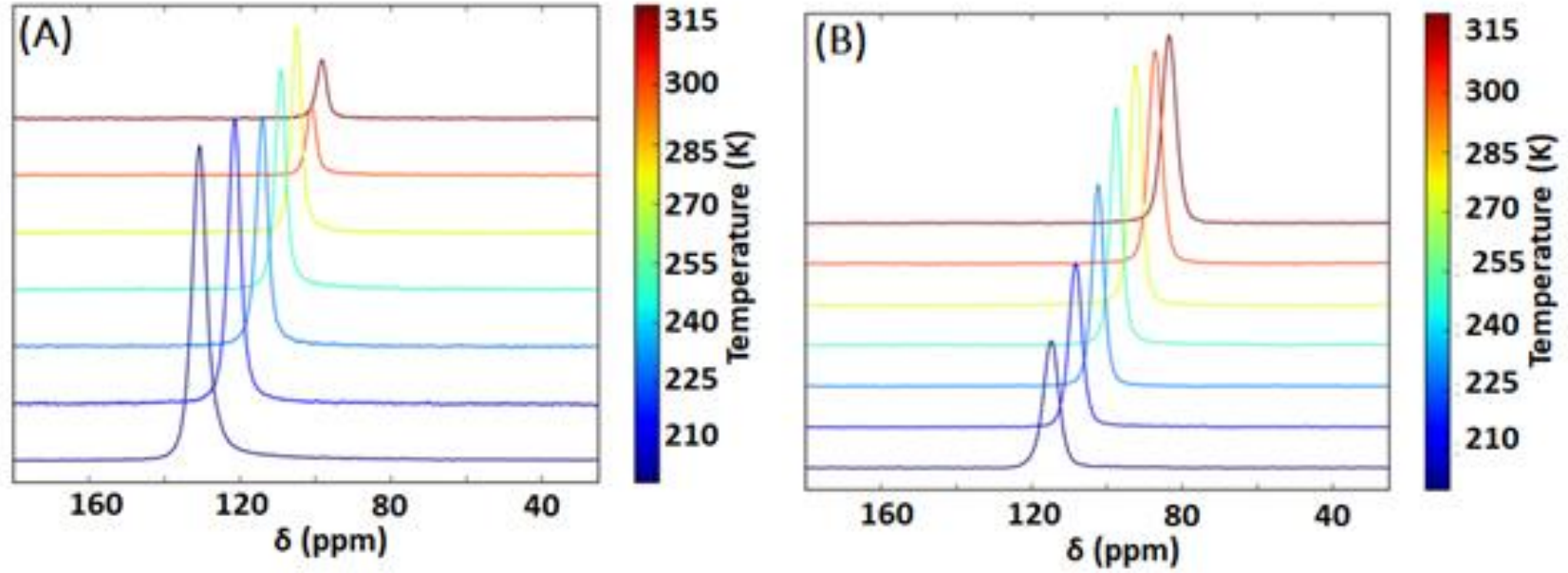

Figure 5. NMR Spectra of HP ${ }^{129} \mathrm{Xe}$ adsorbed on $P_{\mathrm{RT}}$-TPA (A) and $\mathbf{P}_{\mathrm{RT}}$-THA (B) samples recorded at variable temperature (200-320K).

In order to gain more insight into the structure and properties of the embryonic zeolites, the samples are further characterized by thermal analysis (TG/DSC, Figure S6) and ${ }^{13} \mathrm{C} \mathrm{CP}$ MAS NMR spectroscopy, Figure S7. ${ }^{44}$ Prior to TG-analyses, the samples are equilibrated overnight under a $79 \%$ relative humidity at room temperature. The thermograms of different samples are fairly similar to two well established regions, a first, between room temperature and $200-250^{\circ} \mathrm{C}$ and a second between 250 and $500^{\circ} \mathrm{C}$. The weight loss below $200^{\circ} \mathrm{C}$ is associated with an endothermic peak and attributed to water release. The weight loss at higher temperature $\left(250-500^{\circ} \mathrm{C}\right)$ is associated with an exotherm (DSC) and corresponds to the OSDA oxidation. Compared to a crystalline zeolitic material, the embryonic zeolites are much more hydrophilic. For instance, the water content of ZSM-5 is about 5\%, while its amorphous counterpart synthesized with TPA contains about $35 \mathrm{wt} \%$ water. It is of note that water content increases with the increasing size of the OSDA used, from 38 to 48 and $52 \%$ with TMA, TPA, and THA, respectively. Most of the water is released at about $60^{\circ} \mathrm{C}$ on $\mathrm{P}_{\mathrm{RT}}$-THA and at higher temperatures on samples containing smaller structure directing agents $\left(\mathrm{P}_{\mathrm{RT}}-\right.$ TPA and $\mathrm{P}_{\mathrm{RT}}$-TMA); this further implies that larger (hydrated) OSDAs lead to embryos with more open structures. The OSDA oxidation includes several steps; one common around $280-300^{\circ} \mathrm{C}$, characteristic of weakly bound cations located on the external surface of the embryonic units, and another at higher temperature related to the size of OSDA. With a smaller OSDA, its decomposition is slower due to its confinement and more restricted access of the oxidant $\left(\mathrm{O}_{2}\right)$ highlighted by a shift to higher temperatures $\left(450^{\circ} \mathrm{C}\right.$ in PTMA vs. $350^{\circ} \mathrm{C}$ in PTPA/THA).

${ }^{13} \mathrm{C}$ CP MAS NMR spectroscopy of the embryonic zeolites shows for each carbon frequency a superposition of a narrow signal and a large signal with a slight chemical shift. The narrow signals correspond to OSDA in less restricted environments, most probably located on the external surface of zeolite embryos, while the larger, correspond to OSDA in more confined environments, OSDA occluded into zeolite embryos, Figure S7. This is indicative of OSDA in two dif- ferent environments. ${ }^{45}$ The first sharp one belongs to mobile OSDA, most probably located on the external surface of zeolite embryos, while the second, broader, corresponds to OSDA located in a more confined space. This is consistent with the previously observed two exotherms on the DSC, namely: i) $200-250^{\circ} \mathrm{C}$, OSDA in a loosely confined environment, ii) 250 $500^{\circ} \mathrm{C}$, OSDA in a more confined environment. Moreover, the ${ }^{13} \mathrm{C}$ CP MAS NMR of $\mathrm{TPA}^{+}$occluded in crystalline ZSM-5 has the distinctive splitting of its $\mathrm{C} 3$ (terminal methyl) peak attributed to the presence of two different environments (linear and zig-zag channels) in the zeolite channels. ${ }^{46-47}$ Such a splitting is not observed in $\mathrm{P}_{\mathrm{RT}}$-TPA, indicating the presence of its methyl groups (C3) in a unique environment. A shift of -3 ppm of the $\mathrm{C} 1$ peak in the EZ indicates a more distorted angular configuration of its methylene group attached to the nitrogen as reported earlier. ${ }^{48}$

Figure S8A shows the ${ }^{27} \mathrm{Al}$ NMR spectra of all as-prepared samples, with a single peak centered at 53 ppm characteristic of tetrahedral aluminum. After calcination, Figure S8B, aluminum is present in other coordination: a majority remains in tetrahedral coordination (ca. $53 \mathrm{ppm}$ ), some become octahedral $(0 \mathrm{ppm})$ and a broad peak $(0$ and $-40 \mathrm{ppm})$ appears often attributed to distorted tetrahedral $\mathrm{Al}$ and/or penta-coordinated $\mathrm{Al}$ can be observed. The proportion of non-tetrahedral $\mathrm{Al}$ varies in the different samples. By deconvoluting the spectra using the dm-fit program, the relative fraction of octahedral aluminum is estimated between $38 \%$ ( $\mathrm{P}_{\mathrm{RT}}-\mathrm{TMA}$ ) and $26 \%$ ( $\mathrm{P}_{\mathrm{RT}}$-THA), higher than the $10 \%$ usually observed for a pentasil type zeolite. However, this amount is substantially lower than what is observed in a variety of amorphous aluminosilicates. ${ }^{49}$ This indicates that a substantial portion of $\mathrm{Al}$ is stabilized in a silica matrix and remains there upon calcination at high temperature. The dealumination of zeolites depends on both the framework type and the $\mathrm{T}$ site within a given zeolite. ${ }^{50-51}$ The larger proportion of octahedral $\mathrm{Al}$ is observed in the calcined $\mathrm{P}_{\mathrm{RT}}$-TMA embryos and the lowest in $\mathrm{P}_{\mathrm{RT}}$-THA; this could be related to the bond angles of the alumina-silica species surrounding the template, as the small TMA generates 
an inorganic network with more stress than the larger templates.

The acidity of embryonic samples is characterized by in-situ infrared spectroscopy using pyridine as a probe molecule. The number of Brønsted acid sites (BAS) is calculated from the pyridinium band at $1545 \mathrm{~cm}^{-1}$ after the evacuation of pyridine at different desorption temperature. The results are given in Figure 6.
(A)

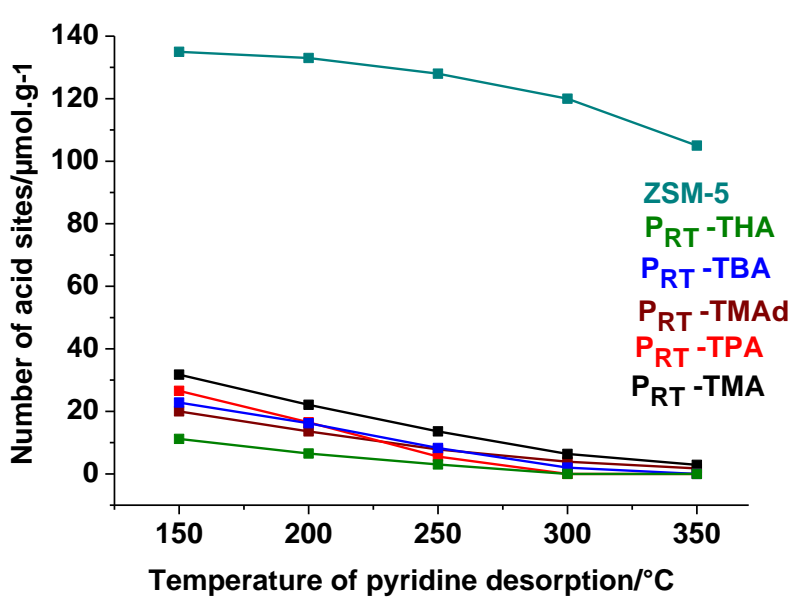

(B)

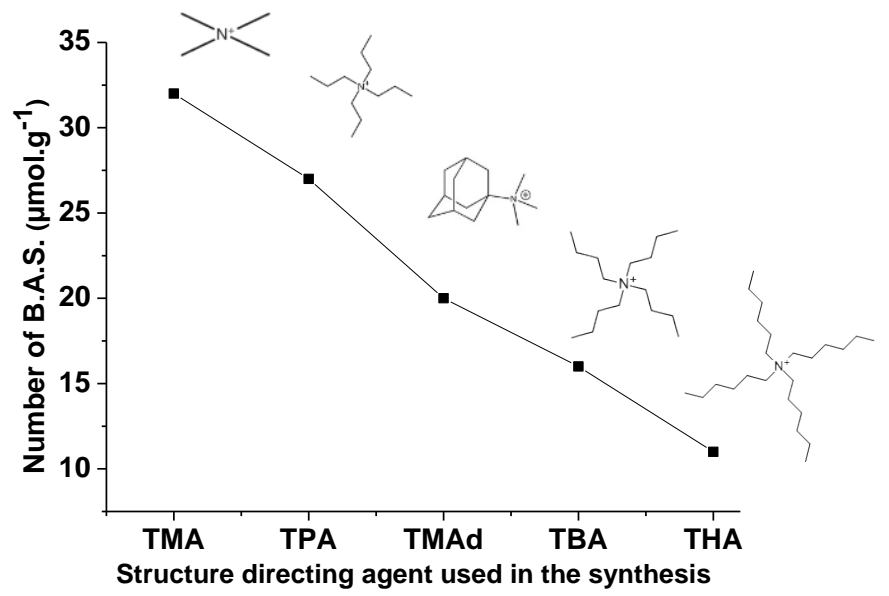

Figure 6. The number of Brønsted acid sites $\left(\mu \mathrm{mol} . \mathrm{g}^{-1}\right)$ for $\mathbf{P}_{\mathrm{RT}}-\mathrm{OSDA}$ and nanosized ZSM-5 at different temperatures determined by TPD of pyridine (A) and at $150^{\circ} \mathrm{C}$ as a function of OSDA size (B).

The embryonic zeolites possess a significantly lower concentration $\left(<40 \mu \mathrm{mol} . \mathrm{g}^{-1}\right)$ and strength of Brønsted acid sites in comparison to ZSM-5 ( 135 $\mu$ mol.g $\left.{ }^{-1}\right)$, attributed to a wider distribution of angular configurations and organization of the alumino-silicate matrix compared to highly crystalline zeolites. After pyridine desorption at $150^{\circ} \mathrm{C}$, the embryonic zeolites have slightly different concentrations of BAS, depending on the employed OSDA. Smaller OSDA leads to higher BAS concentrations (Figure 6B). An increase in the size/charge ratio of an OSDA leading to a decrease in the number of BAS was already reported by Barrer and Denny, ${ }^{52}$ Aeillo and Den$n y^{53}$ and $\operatorname{Kerr}^{54}$ for different zeolites. After desorption at a higher temperature $\left(>250^{\circ} \mathrm{C}\right)$, the number of Brønsted acid sites is close to zero for all samples, indicative of the low acid strength of the embryonic zeolites. By combining ICP-analysis and ${ }^{27} \mathrm{Al} \mathrm{NMR}$ results, it is possible to evaluate the amount of $\mathrm{Al}^{\mathrm{IV}}$ in each sample and, therefore the number of expected BAS. The Pyridine method account, however, fir only $20 \%$ of the expected amount of BAS. This might be due to the presence of BAS in a very confined environment inaccessible to pyridine or the remaining $\mathrm{Al}^{\mathrm{IV}}$ present in the calcined samples does not completely correspond to BAS. Indeed, the peak centered at $53 \mathrm{ppm}$ in ${ }^{27} \mathrm{Al} \mathrm{NMR}$ is not symmetrical and presents an extension between 40 and $10 \mathrm{ppm}$, which can be attributed to highly distorted, tetrahedral, non-framework, aluminum-oxygen species. The chemical shift around $30 \mathrm{ppm}$ is also consistent with penta-coordinated aluminum. ${ }^{55-56} \mathrm{In}$ addition, during calcination, the tetrahedral symmetry of the lattice aluminum must be lost, and aluminum species of low symmetry formed. In a low symmetry environment, aluminum can become "invisible" due to important peak broadening of this quadrupolar nucleus. ${ }^{57-59}$

The accessibility to active sites (B.A.S.) is best studied by infrared spectroscopy of adsorbed probe molecules of different kinetic diameters, namely Pyridine $(0.57 \mathrm{~nm})$ and Collidine $(0.74 \mathrm{~nm}){ }^{35}$ The results of such experiments, performed under similar conditions, are summarized in Figure S9. The number of B.A.S is calculated from the bands associated with protonated pyridine $\left(1545 \mathrm{~cm}^{-1}\right)$ and collidine $\left(1648 \mathrm{~cm}^{-1}\right)$ after their adsorption and evacuation of the physisorbed portion of the adsorbates. The accessibility to B.A.S. is defined as the ratio between the number of B.A.S. measured by collidine and pyridine. While, with the TMA OSDA ( $\mathrm{P}_{\mathrm{RT}}$-TMA), the accessibility is 0.37 , i.e. the sites probed by collidine are less than half of those probed by pyridine $\left(13 \mu \mathrm{mol} . \mathrm{g}^{-1} \mathrm{vs} 36 \mu \mathrm{mol} . \mathrm{g}^{-1}\right)$,

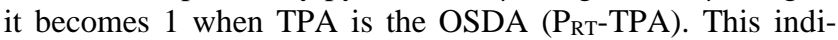
cates that all active sites are accessible to both molecules in the latter. So, in the presence of small OSDA, small pores are formed, restricting accessibility of their Brønsted acid sites to bulky molecules and leading to potential shape selective effects in embryonic zeolites.

${ }^{29} \mathrm{Si}$ NMR spectra of as-synthesized and calcined embryonic zeolites prepared in the presence of the smallest (TMA), medium (TPA) and largest (THA) OSDAs show different silicon environments $\mathrm{Q}^{2}, \mathrm{Q}^{3}$ and $\mathrm{Q}^{4}$ (Figure S10). ${ }^{60}$ Their deconvolution with the dm-fit program gives the relative fraction of each species. After calcination, the chemical shifts are unchanged but the relative areas of $\mathrm{Q}^{2}$ and $\mathrm{Q}^{3}$ decrease while the $\mathrm{Q}^{4}$ increase. These changes result from two simultaneous events upon heating: i) some tetrahedral $\mathrm{Al}$ changing coordination, ii) condensation of some silica species. The calcined samples have almost the same ratio of $\mathrm{Q}^{3}$ and $\mathrm{Q}^{4}$ species but the contribution of $\mathrm{Al}$ and $\mathrm{OH}$ groups to the $\mathrm{Q}^{3}$ species differs between different samples.

Impact of temperature and synthesis time on the physicochemical properties of embryonic zeolites

In addition to room temperature synthesis, embryonic zeolites are prepared at $90^{\circ} \mathrm{C}$ during $12-216 \mathrm{~h}$. As with the RT syntheses, all samples are freeze-dried before further processing and characterization. 
The synthesis time is carefully controlled to obtain preformed units with only short-range order. Only the system containing TPA yields a crystalline phase (MFI-type) in syntheses longer than $24 \mathrm{~h}$. The other systems are always amorphous after crystallization up to $216 \mathrm{~h}$ (Figure S11).

The ${ }^{13} \mathrm{C}$ CP MAS NMR of the TMA, TPA, and THA templates and the embryonic zeolites synthesized at RT and $90^{\circ} \mathrm{C}$ are displayed in Figure S7. All characteristic peaks of the template are present in the spectra of the embryonic zeolites. Peak broadening, an indication of the presence of the template in a confined environment, is observed.

Like the embryonic zeolites obtained at RT, the solids synthesized at $90^{\circ} \mathrm{C}$ exhibit a type I adsorption isotherm characteristic of a microporous material. In general, the materials synthesized at $90^{\circ} \mathrm{C}$ show an increase in nitrogen uptake with respect to their counterpart obtained at RT, Figure S12. This suggests a better structuring of these embryonic zeolites. The maximum micropore volume is achieved after different synthesis times for different templates. For instance, it is $12 \mathrm{~h}$ for a TPA synthesis and it decreases after $18 \mathrm{~h}$, Figure $\mathbf{S 1 2 B}$; this is related to the onset of crystallization of MFI. With TBA, there is no difference between 15 and 144 h, Figure S12C, while with TMAd the micropore volume increases up to $216 \mathrm{~h}$ of hydrothermal synthesis. The single exception is with THA, where the $90^{\circ} \mathrm{C}$ synthesis shows a lower pore volume and surface area $\left(0.38 \mathrm{~cm}^{3} \cdot \mathrm{g}-1\right.$ and $\left.911 \mathrm{~cm}^{2} . \mathrm{g}-1\right)$ than its RT counterpart $\left(0.47 \mathrm{~cm}^{3} \cdot \mathrm{g}^{-1}\right.$ and $\left.1095 \mathrm{~cm}^{2} \cdot \mathrm{g}^{-1}\right)$, Figure S12E and Table $\mathbf{S 2}$.
It is difficult to determine the reason for such a trend but could be related to the large size of the THA molecule and a more efficient condensation of the aluminosilicate species at a higher temperature.

The effect of synthesis temperature on the state of $\mathrm{Al}$ in the embryonic zeolites is investigated by ${ }^{27} \mathrm{Al}$ MAS NMR and IR monitored pyridine desorption. The ${ }^{27} \mathrm{Al}$ MAS NMR spectra of all as-synthesized samples exhibit a single peak (ca. $53 \mathrm{ppm}$ ) indicating the sole presence of tetrahedral aluminum, Figure S13. However, after calcination at $550^{\circ} \mathrm{C}$, the intensity of this peak decreases, indicating that a portion of aluminum leaves its tetrahedral coordination. At the same time, two peaks emerge: a sharp and small at $0 \mathrm{ppm}$, typical for octahedrally coordinated aluminum, and a broad between 0 and $-30 \mathrm{ppm}$, attributed to the presence of different polymorph of aluminum. Deconvolution of these spectra with the dm-fit program can evaluate the amount of nontetrahedral aluminum. The octahedral aluminum content decreases in the $90^{\circ} \mathrm{C}$ synthesis. The tetrahedral aluminum peak $(53 \mathrm{ppm})$ is not symmetrical in all samples and tails between 40 and $10 \mathrm{ppm}$. As mentioned above, this can be attributed to the presence of highly distorted, tetrahedral, non-framework, aluminum-oxygen species or penta-coordinate aluminum.

IR spectroscopy of adsorbed pyridine measures the acidity of the embryonic zeolites. The number of Brønsted acid sites, calculated from the pyridinium ion band $\left(1545 \mathrm{~cm}^{-1}\right)$, are summarized

in

Table

Table 1. Number of Brønsted acid sites $\left(\mu \mathrm{mol} . \mathrm{g}^{-1}\right)$ of P-OSDA prepared at RT and at $90^{\circ} \mathrm{C}$.

\begin{tabular}{|c|c|c|c|c|c|c|c|c|c|c|c|c|c|}
\hline Embryonic & \multicolumn{3}{|c|}{ P-TMA } & \multicolumn{3}{|l|}{ P-TPA } & \multicolumn{2}{|c|}{ P-TMAd } & \multicolumn{2}{|c|}{ P-TBA } & \multicolumn{2}{|c|}{ P-THA } & \multirow[t]{2}{*}{ ZSM-5 } \\
\hline Temperature & RT & $\mathbf{P}_{90-15}$ & RT & $\mathbf{P}_{90-15}$ & $\mathbf{P}_{90-18}$ & RT & $\mathbf{P}_{90-15}$ & $\mathbf{P}_{90-216}$ & $\mathbf{P}_{90-15}$ & $\mathbf{P}_{90-144}$ & RT & $\mathbf{P}_{90-144}$ & \\
\hline 150 & 32 & 34 & 27 & 35 & 38 & 20 & 40 & 37 & 23 & 20 & 11 & 22 & 135 \\
\hline 200 & 22 & 23 & 17 & 27 & 29 & 14 & 27 & 26 & 16 & 15 & 7 & 15 & 133 \\
\hline 250 & 14 & 12 & 6 & 18 & 18 & 8 & 15 & 15 & 8 & 7 & 3 & 7 & 128 \\
\hline 300 & 6 & 5 & $\mathbf{0}$ & 8 & 9 & 4 & 5 & 6 & 2 & 0 & $\mathbf{0}$ & 0 & 120 \\
\hline 350 & 3 & 1 & $\mathbf{0}$ & 2 & 2 & 2 & 2 & 1 & 0 & 0 & 0 & 0 & 105 \\
\hline
\end{tabular}

The acidity of the EZ prepared at $90^{\circ} \mathrm{C}$ increases with synthesis time, but differences are marginal. As for the room temperature EZ syntheses, the smaller the OSDA, the higher the number of BAS; differences, however, are not substantial and all EZ possess a much lower number of acid sites than ZSM-5 with similar $\mathrm{Si} / \mathrm{Al}$ ratio.

\section{Catalytic activity}

Earlier studies showed that amorphous zeolite precursors compelling catalytic performances in hydrocarbon conversion. ${ }^{61-62}$ In the present work, we evaluated the catalytic performances of embryonic zeolites prepared at RT in the dealkylation of triisopropylbenzene (TiPBz), Figure 7A. Its kinetic diameter $(0.95 \mathrm{~nm})$, is well above the pore openings of the MFI-type zeolite $(0.56 \mathrm{~nm})$ and $\mathrm{TiPBz}$ is therefore com- monly used to study the external surface properties of zeolites, including the large pores (12 MR) ones.

$\mathrm{P}_{\mathrm{RT}}$-TMAd and $\mathrm{P}_{\mathrm{RT}}$-TMA EZ lead to the highest and the lowest conversion, respectively, Figure 7A. Figure 7B highlights the effects of the OSDA on the conversion, number of Brønsted acid sites and micropore volume. While $\mathrm{P}_{\mathrm{RT}}$-TMA possesses the highest number of Brønsted acid sites, its smallest conversion of $\mathrm{TiPBz}$ is related to the limited accessibility of its acid sites. This clearly indicates that the OSDA size is a tool to control the size selectivity of the EZ. For instance, TPA and TMAd generated materials comprise relatively strong Brønsted acid sites in micropores large enough to process TiPBz. Conversely, the larger TBA and THA OSDA generate EZ with larger micropores accessible to bulky molecules, but their catalytic performances are low due to a lack of Brønsted acid sites. Thus, EZ combining a critical number of active sites 
with pores opening large enough to transport the bulky TiPBZ display the best catalytic performances; the catalytic properties of embryonic zeolites can be tuned by accessibility and ac$\mathrm{id} /$ active site density.

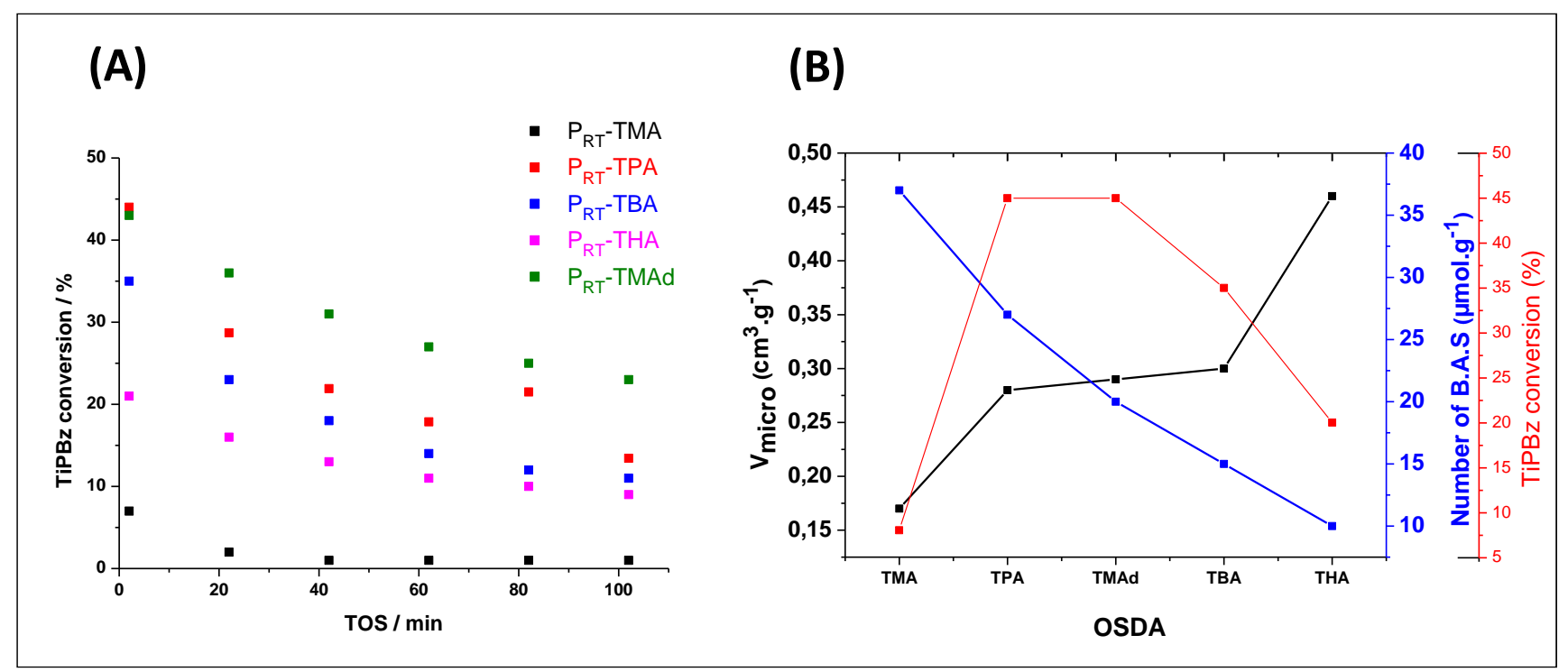

Figure 7. (A) TiPBz conversion of RT synthesized embryonic zeolites (A). (B) TiPBz conversion, number of BrØnsted acid sites and micropore volume of the embryonic zeolites as a function of OSDA in the synthesis. Catalytic test conditions: $\mathrm{T}=300^{\circ} \mathrm{C}$, $\mathrm{WHSV}=\mathbf{8 h}-1$, TOS $=2 \mathrm{~min}$.

\section{CONCLUSIONS}

X-ray amorphous zeolite precursors, the so-called embryonic zeolites (EZ) are prepared with OSDA identical to those used in the synthesis of conventional zeolites. The synthesis conditions need to be controlled to obtain monodisperse suspensions of zeolite precursor particles with a size of a few nanometers. A thorough physicochemical characterization indicates that such zeolite precursors are highly uniform, and their properties strongly depend on the template used. All are microporous materials as the majority of their pores are in the range 1-2 nm. Some exhibit impressive specific surface area $\left(1095 \mathrm{~cm}^{2} \cdot \mathrm{g}^{-1}\right)$ and micropore volume $\left(0.47 \mathrm{~cm}^{3} \cdot \mathrm{g}^{-1}\right)$, larger than that of zeolites obtained with the same template. They are stable upon calcination and can be used as heterogeneous catalysts. While they possess a relatively low number of active sites of moderate acid strength, they display a high activity in bulky molecules conversion as their performance depends on and can be tuned by controlling their acidity and the accessibility of their active sites. EZ, therefore, extends the range of applications of current zeolites especially for bulky molecules; these are encountered in the processing of heavy oil fractions and biomass.

\section{ASSOCIATED CONTENT}

\section{Supporting Information}

The Supporting Information is available free of charge on the ACS Publications website at DOI:

Characterization data: XRD, SEM, FTIR, $\mathrm{N}_{2}$ adsorption/desorption, Pore size distribution (DFT calculation), TG/DSC, NMR (pdf).

\section{AUTHOR INFORMATION}

\section{Corresponding Author}

*E-mail : valentin.valtchev@ensicaen.fr

\section{ORCID :}

Mariame Akouche: 0000-0003-0490-7825

Valentin valtchev: 0000-0002-2341-6397

\section{Author Contributions}

All authors have given approval to the final version of the manuscript.

\section{Funding Sources}

This research was supported by TOTAL Raffinage Marketing and the Industrial Chair ANR-TOTAL "Nanoclean Energy".

Notes

The authors declare no competing financial interest.

\section{ACKNOWLEDGMENT}

The financial support from TOTAL Raffinage Marketing and the Industrial Chair ANR-TOTAL "Nanoclean Energy". V.V. and S.M. acknoweldege the financial support from the CARNOT-ESP 3DNANOZET 5281. GENESIS is supported by the Région Haute-Normandie, the Métropole Rouen Normandie, the CNRS via LABEX EMC and the French National Research Agency as a part of the program "Investissements d'avenir" with the reference ANR-11-EQPX-0020. The authors appreciate the technical support of Marie Desmurs. 


\section{REFERENCES}

(1) Flanigen, E. M.; Broach, R. W.; Wilson, S. T. In Zeolites in

Industrial Separation and Catalysis; Kulprathipanja, S., Ed.; Wiley-VCH: Weinheim, Germany, 2010; pp 1-26.

(2) Bellussi, G.; Carati, A.; Millini, R. In Zeolites and Catalysis:Synthesis, Reactions and Applications; Cejka, J., Corma, A., Zones, S., Eds.; Wiley-VCH: Weinheim, Germany, 2010; pp 449-491.

(3) Marcilly, C. R., Where and how shape selectivity of molecular sieves operates in refining and petrochemistry catalytic processes. Topics in Catalysis 2000, 13 (4), 357-366.

(4) Vermeiren, W.; Gilson, J.-P., Impact of zeolites on the petroleum and petrochemical industry. Topics in Catalysis 2009, 52 (9), 1131-1161.

(5) Martínez, C.; Corma, A., Inorganic molecular sieves: Preparation, modification and industrial application in catalytic processes. Coordination Chemistry Reviews 2011, 255 (13-14), 1558-1580.

(6) Landau, M. V.; Vradman, L.; Valtchev, V.; Lezervant, J.; Liubich, E.; Talianker, M., Hydrocracking of heavy vacuum gas oil with a $\mathrm{Pt} / \mathrm{H}$-beta- $\mathrm{Al} 2 \mathrm{O} 3$ catalyst: effect of zeolite crystal size in the nanoscale range. Industrial \& engineering chemistry research 2003, 42 (12), 2773-2782.

(7) Corma, A.; Fornes, V.; Pergher, S.; Maesen, T. L.; Buglass, J., Delaminated zeolite precursors as selective acidic catalysts. Nature 1998, 396 (6709), 353.

(8) Vuong, G.-T.; Do, T.-O., A new route for the synthesis of uniform nanozeolites with hydrophobic external surface in organic solvent medium. Journal of the American Chemical Society 2007, 129 (13), 3810-3811.

(9) Choi, M.; Na, K.; Kim, J.; Sakamoto, Y.; Terasaki, O.; Ryoo, R., Stable single-unit-cell nanosheets of zeolite MFI as active and long-lived catalysts. Nature 2009, 461 (7261), 246.

(10) Tsapatsis, M.; Fan, W., A New, Yet Familiar, Lamellar Zeolite. ChemCatChem 2010, 2 (3), 246-248.

(11) Smaïhi, M.; Gavilan, E.; Durand, J.-O.; Valtchev, V. P., Colloidal functionalized calcined zeolite nanocrystals. Journal of Materials Chemistry 2004, 14 (8), 1347-1351.

(12) Xu, D.; Abdelrahman, O.; Ahn, S. H.; Guefrachi, Y.; Kuznetsov, A.; Ren, L.; Hwang, S.; Khaleel, M.; Al Hassan, S.; Liu, D., A quantitative study of the structure-activity relationship in hierarchical zeolites using liquid-phase reactions. AIChE Journal 2019, 65 (3), 1067-1075.

(13) Chal, R.; Gérardin, C.; Bulut, M.; Van Donk, S., Overview and industrial assessment of synthesis strategies towards zeolites with mesopores. ChemCatChem 2011, 3 (1), 67-81.

(14) Perez-Ramirez, J.; Christensen, C. H.; Egeblad, K.; Christensen, C. H.; Groen, J. C., Hierarchical zeolites: enhanced utilisation of microporous crystals in catalysis by advances in materials design. Chemical Society Reviews 2008, 37 (11), 2530-2542.

(15) Valtchev, V.; Majano, G.; Mintova, S.; Pérez-Ramírez, J., Tailored crystalline microporous materials by post-synthesis modification. Chemical Society Reviews 2013, 42 (1), 263 290.
(16) Wei, Y.; Parmentier, T. E.; de Jong, K. P.; Zečević, J., Tailoring and visualizing the pore architecture of hierarchical zeolites. Chemical Society Reviews 2015, 44 (20), 7234-7261.

(17) Valtchev, V.; Balanzat, E.; Mavrodinova, V.; Diaz, I.; El Fallah, J.; Goupil, J.-M., High energy ion irradiation-induced

ordered macropores in zeolite crystals. Journal of the American Chemical Society 2011, 133 (46), 18950-18956.

(18) Haw, K.-G.; Gilson, J.-P.; Nesterenko, N.; Akouche, M.; El Siblani, H.; Goupil, J.-M.; Rigaud, B.; Minoux, D.; Dath, J.-P.; Valtchev, V., Supported Embryonic Zeolites and their Use to Process Bulky Molecules. ACS Catalysis 2018, 8 (9), 8199-8212.

(19) Jiang, J.; Yu, J.; Corma, A., Extra-large-pore zeolites: bridging the gap between micro and mesoporous structures. Angewandte Chemie International Edition 2010, 49 (18), 3120-3145.

(20) Manton, M. R.; Davidtz, J. C., Controlled pore sizes and active site spacings determining selectivity in amorphous silica-alumina catalysts. Journal of Catalysis 1979, 60 (1), $156-166$.

(21) Corma, A.; Pérez-Pariente, J.; Fornés, V.; Rey, F.; Rawlence, D., Synthesis and characterization of silica-alumina prepared from tetraalkylammonium hydroxides. Applied Catalysis 1990, 63 (1), 145-164.

(22) Camblor, M. A.; Corell, C.; Corma, A.; Díaz-Cabañas, M.-J.; Nicolopoulos, S.; González-Calbet, J. M.; Vallet-Regí, M., A new microporous polymorph of silica isomorphous to zeolite MCM-22. Chemistry of materials 1996, 8 (10), 24152417.

(23) Cantín, A.; Corma, A.; Diaz-Cabanas, M. J.; Jordá, J. L.; Moliner, M., Rational design and HT techniques allow the synthesis of new IWR zeolite polymorphs. Journal of the American Chemical Society 2006, 128 (13), 4216-4217.

(24) Liu, Z.; Ohsuna, T.; Terasaki, O.; Camblor, M. A.; DiazCabañas, M.-J.; Hiraga, K., The first zeolite with threedimensional intersecting straight-channel system of 12membered rings. Journal of the American Chemical Society 2001, 123 (22), 5370-5371.

(25) Szostak, R. In Handbook of molecular sieves: structures. Springer Science \& Business Media: New-York, 1992.

(26) Peng, C.; Liu, Z.; Yonezawa, Y.; Linares, N.; Yanaba, Y.; Trujillo, C. A.; Okubo, T.; Matsumoto, T.; García-Martínez, J.; Wakihara, T., Testing the limits of zeolite structural flexibility: ultrafast introduction of mesoporosity in zeolites. Journal of Materials Chemistry A 2020, 8 (2), 735-742.

(27) S-Aguiar, E. F.; Murta-Valle, M.; Sobrinho, E.; Cardoso, D., Cracking of 1, 3, 5-triisopropylbenzene over deeply dealuminated Y zeolite. In Studies in Surface Science and Catalysis, Elsevier: Canada, 1995, pp 417-422.

(28) Chateigner, D., Ed. In Combined Analysis: Structuretexture-microstructure-phase-stresses-reflectivity analysis by $X$-ray and neutron scattering, Wiley-ISTE: France, $2010 \mathrm{p}$ 496.

(29) Lutterotti, L., Total pattern fitting for the combined sizestrain-stress-texture determination in thin film diffraction. Nuclear Instruments and Methods in Physics Research Section B: Beam Interactions with Materials and Atoms 2010, 268 (3-4), 334-340. 
(30) Rietveld, H., A profile refinement method for nuclear and magnetic structures. Journal of applied Crystallography 1969, 2 (2), 65-71.

(31) Popa, N., The (hkl) dependence of diffraction-line broadening caused by strain and size for all Laue groups in Rietveld refinement. Journal of Applied Crystallography 1998, 31 (2), 176-180.

(32) Gražulis, S.; Chateigner, D.; Downs, R. T.; Yokochi, A.; Quirós, M.; Lutterotti, L.; Manakova, E.; Butkus, J.; Moeck, P.; Le Bail, A., Crystallography Open Database-an openaccess collection of crystal structures. Journal of applied crystallography 2009, 42 (4), 726-729.

(33) Happer, W., Optical pumping. Reviews of Modern Physics 1972, 44 (2), 169.

(34) Happer, W.; Miron, E.; Schaefer, S.; Schreiber, D.; Van Wijngaarden, W.; Zeng, X., Polarization of the nuclear spins of noble-gas atoms by spin exchange with optically pumped alkali-metal atoms. Physical Review A 1984, 29 (6), 3092.

(35) Nesterenko, N.; Thibault-Starzyk, F.; Montouilliout, V.; Yushchenko, V.; Fernandez, C.; Gilson, J.-P.; Fajula, F.; Ivanova, I., The use of the consecutive adsorption of pyridine bases and carbon monoxide in the IR spectroscopic study of the accessibility of acid sites in microporous/mesoporous materials. Kinetics and catalysis 2006, 47 (1), 40-48.

(36) Pichat, P.; Franco-Parra, C.; Barthomeuf, D., Infra-red structural study of various type $\mathrm{L}$ zeolites. Journal of the Chemical Society, Faraday Transactions 1: Physical Chemistry in Condensed Phases 1975, 71, 991-996.

(37) Jansen, J.; Van der Gaag, F.; Van Bekkum, H., Identification of ZSM-type and other 5-ring containing zeolites by ir spectroscopy. Zeolites 1984, 4 (4), 369-372.

(38) Thommes, M.; Kaneko, K.; Neimark, A. V.; Olivier, J. P.; Rodriguez-Reinoso, F.; Rouquerol, J.; Sing, K. S., Physisorption of gases, with special reference to the evaluation of surface area and pore size distribution (IUPAC Technical Report). Pure and Applied Chemistry 2015, 87 (9-10), 10511069.

(39) Derouane, E. G.; Determmerie, S.; Gabelica, Z.; Blom, N., Synthesis and characterization of ZSM-5 type zeolites I. physico-chemical properties of precursors and intermediates. Applied catalysis 1981, 1 (3-4), 201-224.

(40)Gittleman, C.; Bell, A.; Radke, C., Role of tetrapropylammonium cations in gel-phase silicalite synthesis. Microporous Materials 1994, 2 (2), 145-158.

(41) Corma, A.; Díaz-Cabañas, M. J.; Martínez-Triguero, J.; Rey, F.; Rius, J., A large-cavity zeolite with wide pore windows and potential as an oil refining catalyst. Nature 2002, 418 (6897), 514.

(42) Corma, A.; Díaz-Cabañas, M. J.; Rey, F.; Nicolopoulus, S.; Boulahya, K., ITQ-15: The first ultralarge pore zeolite with a bi-directional pore system formed by intersecting 14-and 12ring channels, and its catalytic implications. Chemical Communications 2004, (12), 1356-1357.

(43) Chen, F.; Chen, C.-L.; Ding, S.; Yue, Y.; Ye, C.; Deng, F., A new approach to determination of micropore size by 129Xe NMR spectroscopy. Chemical physics letters 2004, 383 (3-4), 309-313.

(44) Gabelica, Z.; Derouane, E.; Gilson, J.-P., The use of combined thermal analysis to study crystallization, pore structure, catalytic activity and deactivation of synthetic zeolites. Clay Minerals 1984, 19 (5), 803-824.

(45) Gittleman, C.; Watanabe, K.; Bell, A.; Radke, C., A mechanistic study of the synthesis of zeolite SSZ-24. Microporous materials 1996, 6 (3), 131-150.
(46) Boxhoorn, G.; van Santen, R. A.; van Erp, W. A.; Hays, G. R.; Huis, R., An investigation into the structure and position of organic bases in ZSM-5-type zeolites by highresolution solid-state $13 \mathrm{C} \mathrm{nmr} \mathrm{spectroscopy.} \mathrm{Journal} \mathrm{of} \mathrm{the}$ Chemical Society, Chemical Communications 1982, (4), 264265.

(47) Nagy, J. B.; Gabelica, Z.; Derouane, E. G., Position and configuration of the guest organic molecules within the framework of the ZSM-5 and ZSM-11 zeolites. Zeolites 1983, 3 (1), 43-49.

(48) Dib, E.; Gimenez, A.; Mineva, T.; Alonso, B., Preferential orientations of structure directing agents in zeolites. Dalton Transactions 2015, 44 (38), 16680-16683.

(49) Welsha, L.; Gilson, J.-P.; Gattuso, M., High resolution 27Al NMR of amorphous silica-aluminas. Applied catalysis 1985, 15 (2), 327-331.

(50) Silaghi, M.-C.; Chizallet, C.; Petracovschi, E.; Kerber, T.; Sauer, J.; Raybaud, P., Regioselectivity of Al-O Bond Hydrolysis during Zeolites Dealumination Unified by Brønsted-Evans-Polanyi Relationship. ACS Catalysis 2014, 5 (1), 11-15.

(51) Karwacki, L.; de Winter, D. M.; Aramburo, L. R.; Lebbink, M. N.; Post, J. A.; Drury, M. R.; Weckhuysen, B. M., Architecture-dependent distribution of mesopores in steamed zeolite crystals as visualized by FIB-SEM tomography. Angewandte Chemie International Edition 2011, 50 (6), 1294-1298.

(52) Barrer, R.; Denny, P., 202. Hydrothermal chemistry of the silicates. Part X. A partial study of the field $\mathrm{CaO}-\mathrm{Al} 2 \mathrm{O}$ 3-SiO 2-H 2 O. Journal of the Chemical Society (Resumed) 1961, 983-1000.

(53) Aiello, R.; Barrer, R., Hydrothermal chemistry of silicates. Part XIV. Zeolite crystallisation in presence of mixed bases. Journal of the Chemical Society A: Inorganic, Physical, Theoretical 1970, 1470-1475.

(54) Kerr, G. T., Chemistry of crystalline aluminosilicates. II. The synthesis and properties of zeolite ZK-4. Inorganic Chemistry 1966, 5 (9), 1537-1539.

(55) Campbell, S. M.; Bibby, D. M.; Coddington, J. M.; Howe, R. F.; Meinhold, R. H., Dealumination of HZSM-5 zeolites: I. Calcination and hydrothermal treatment. Journal of Catalysis 1996, 161 (1), 338-349.

(56) Gilson, J.-P.; Edwards, G. C.; Peters, A. W.; Rajagopalan, K.; Wormsbecher, R. F.; Roberie, T. G.; Shatlock, M. P., Penta-co-ordinated aluminium in zeolites and aluminosilicates. Journal of the Chemical Society, Chemical Communications 1987, (2), 91-92.

(57) Klinowski, J.; Thomas, J.; Fyfe, C.; Gobbi, G., Monitoring of structural changes accompanying ultrastabilization of faujasitic zeolite catalysts. Nature 1982, 296 (5857), 533.

(58) Fyfe, C.; Gobbi, G.; Kennedy, G., Investigation of the conversion (dealumination) of ZSM-5 into silicalite by highresolution solid-state silicon-29 and aluminum-27 MAS NMR spectroscopy. The Journal of Physical Chemistry 1984, 88 (15), 3248-3253.

(59) Maijanen, A.; Derouane, E. G.; Nagy, J. B., FT-IR and solid-state NMR investigation of surface hydroxyl groups on dealuminated ZSM-5. Applied surface science 1994, 75 (1-4), 204-212.

(60) Boxhoorn, G.; Kortbeek, A.; Hays, G.; Alma, N., A highresolution solid-state29 Si nmr study of ZSM-5 type zeolites. Zeolites 1984, 4 (1), 15-21. 
(61) Jacobs, P. A.; Derouane, E. G.; Weitkamp, J., Evidence for X-ray-amorphous zeolites. Journal of the Chemical Society, Chemical Communications 1981, (12), 591-593.

(62) Bellussi, G.; Perego, C.; Carati, A.; Peratello, S.; Massara, E. P.; Perego, G., Amorphous mesoporous silica- alumina with controlled pore size as acid catalysts. In Studies in Surface Science and Catalysis, Elsevier: Germany, 1994; Vol. 84, pp 85-92.
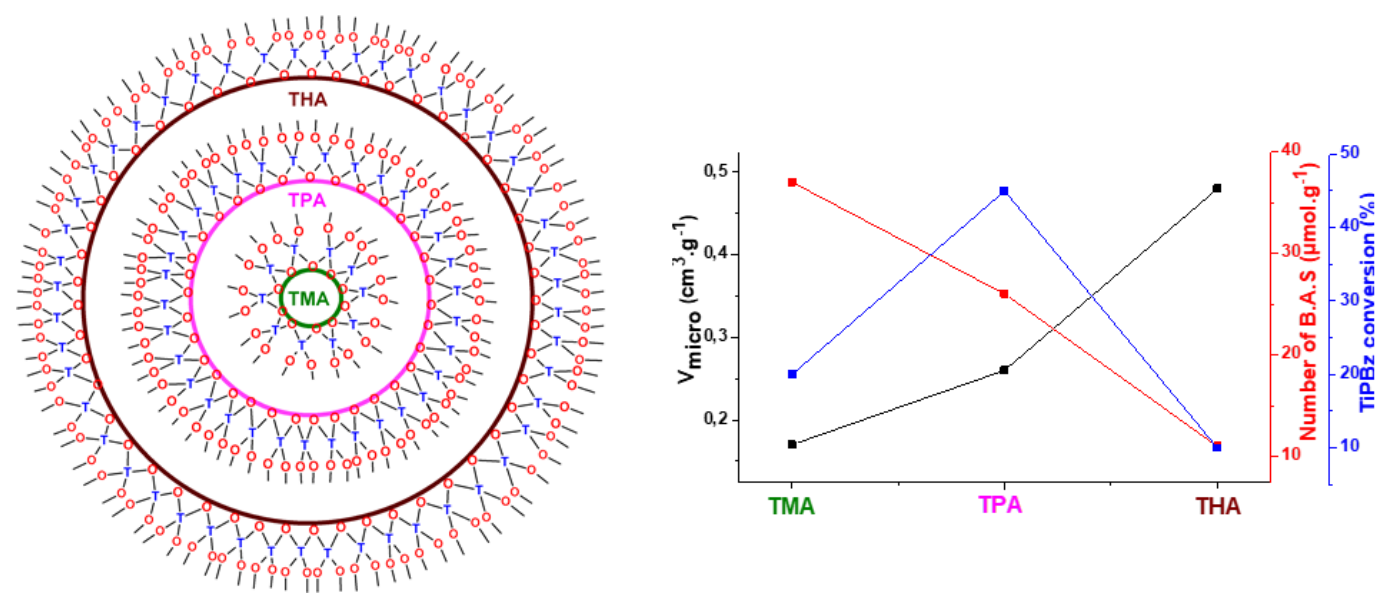